\title{
Experimental Research on Vibration and Noise Reduction of Vehicular Vacuum Circuit Breaker's Equipment Box
}

\author{
Song Leiming*, Zhang Jiayu, Chen Hao \\ School of Mechanical, Electronic and Control Engineering, Beijing Jiaotong University, Beijing, China \\ Email address: \\ lmsong@bjtu.edu.cn (Song Leiming),16121333@bjtu.edu.cn (Zhang Jiayu),16121313@ bjtu.edu.cn (Chen Hao) \\ ${ }^{*}$ Corresponding author
}

\section{To cite this article:}

Song Leiming, Zhang Jiayu, Chen Hao. Experimental Research on Vibration and Noise Reduction of Vehicular Vacuum Circuit Breaker's Equipment Box. Science Discovery. Vol. 6, No. 2, 2018, pp. 85-92. doi: 10.11648/j.sd.20180602.12

Received: April 19, 2018; Accepted: May 17, 2018; Published: June 22, 2018

\begin{abstract}
Through the test method of bench test, the vibration and noise condition of vehicle vacuum circuit breaker equipment box is analyzed under several measures for vibration and noise reduction, which provides important basis for vibration and noise reduction and low noise design of this device. The experimental results show that the damping effect is not obvious when adding the damping washer between the installation panel of main circuit breaker and the installation box girder. Adding vibration isolation sponge and rubber shock absorber on the contact surface between the platform and the box has a certain effect on alleviating the vibration of the bench and reducing the noise at the bottom of the box, and the effect of vibration and noise reduction from shock absorber is better compared with the vibration isolation sponge.
\end{abstract}

Keywords: Vehicular Vacuum Circuit Breaker, High Pressure Equipment Box, Vibration and Noise Reduction

\section{车载高压真空断路器设备箱的减振降噪试验研究}

\author{
宋雷鸣”, 张佳宇, 陈浩 \\ 机械与电子控制工程学院, 北京交通大学, 北京, 中国
}

邮箱:

Imsong@bjtu.edu.cn (宋雷鸣),16121333@bjtu.edu.cn(张佳宇),16121313@bjtu.edu.cn(陈浩)

\begin{abstract}
摘要: 通过台架实验的测试手段, 分析几种减振降噪措施下车载真空断路器设备箱的振动噪声状况, 为实车该装置减 振降噪及低噪声化设计提供重要依据。实验结果表明, 在主断路器安装面板与设备箱安装梁之间加入阻尼垫圈, 减振 效果并不明显, 在台架与箱体之间接触面上增加减振泡棉和橡胶减振器对于缓解台架振动和降低箱体下部噪声有一定 效果, 且减振器的减振降噪效果要好于减振泡绵。
\end{abstract}

关键词: 车载真空断路器, 设备箱, 减振降噪

\section{1. 引言}

车载真空主断路器 (VCB) 是保障列车日常供电安全 的重要电气设备[1]。其不仅能够承载、开合运行回路的正 常电流, 也能在一定的时间内承受、开合规定的过载电流
（包含短路电流）[2]。在工作过程中还要经受电、热、机 械力、大气环境等因素的作用 [3]。在列车的实际运行中, VCB用来切断故障电流和短路电流方面的概率很低, 其断 开和闭合动作基本都发生在列车过分相或作为主电路分 合总开关工作 [4-5]。在列车通过分相段前, VCB断开, 将 列车主电路同受电弓、接触网分离, 通过分相段后该装置 
又重新闭合[6-7]。在此过程中, 由VCB开闭引起的振动噪 声在列车车厢中感受明显, 严重影响了列车内乘客的乘坐 舒适性。目前, 国内针对 VCB的研究是从故障及寿命的角 度出发的 [8-12]。针对列车实际运行工况下VCB的减振降 噪研究还不完善, 尤其是缺少针对性和试验性的减振降噪 研究。本文力求通过VCB设备箱的台架试验, 找出降低列 车过分相等 $\mathrm{VCB}$ 频繁开合工况下引起的设备箱体的振动 噪声方案, 为高速铁路的减振降噪提供重要依据。

\section{2. 试验方法的说明}

振动噪声都可从源、传播路径及接收体三部分进行控 制[13], 最根本也是最有效的方式就是从源头入手进行减 振降噪 [14]。而由于VCB的内部结构复杂, 进行减振降噪 的成本较高, 最终选择在振动噪声的传播路径上进行减振 降噪。试验采取台架测试[15], 将设备箱体坐在台架上, 用台架的振动模拟实际工况中由于箱体振动引起的列车 车体的振动, 用设备箱体下部噪声表征实际工况中VCB工 作时传到高压设备箱外的噪声。根据设备结构, 确定 VCB 传到车体的振动传递路径如图1所示:

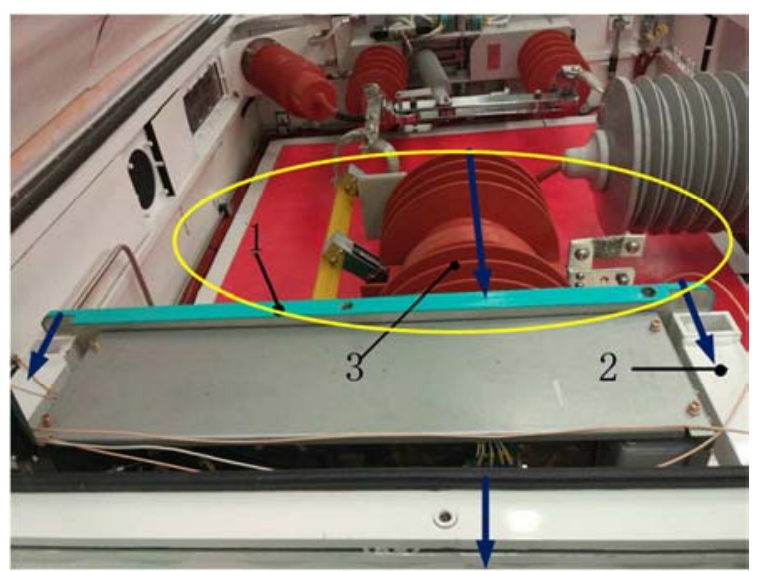

图1 VCB设备箱振动传递路径图。
图1中标记的位置为 $\mathrm{VCB}$ 。 VCB闭合或断开, 产生振 动, 传到安装面板 1 , 安装面板与箱体内部的安装梁 2 用螺 栓连接, 振动随螺栓传到安装梁 2 , 安装梁 2 与整个箱体焊 接, 因此, 振动就传到了箱体上, 设备箱箱体与台架直接 刚性连接, 振动就直接传到了台架上。在实际工况中, VCB 安装在车顶, 其安装座的振动传递到车体上, 进而由车体 向车内辐射噪声。

列车运行中, 乘客对 $\mathrm{VCB}$ 开合时由振动激励而产生的 二次噪声感受明显。本研究目的在于采取有效的技术措施 减少 VCB开合时产生的振动向台架传播, 从而在实际结构 中降低车体的振动及减少噪声辐射, 降低车内噪声。

目前常规的减振措施包含: 加阻尼材料、加橡胶减振 器、减振泡棉、减振夹层等。由于实际的安装尺寸和减振 降噪成本的限制, 本文选取加装阻尼垫圈、橡胶减振器和 减振泡棉三种减振措施进行对比研究, 为实车减振降噪提 供参考。

\section{3. 台架试验}

\section{1. 试验设计}

基于上述振动的传递路径, 可以确定台架试验的振动 测点, 测点布置如图2, 测点对称布置, 测点 $1 、 2$ 与测点 $3 、$ 4 对称布置, 位于高压设备箱内部, 测点5、6 与测点 $7 、 8$ 对称布置, 这四个测点位于高压设备箱外部。测点位置说 明见表 1 。

表1 实际测点的位置。

\begin{tabular}{ll}
\hline 测点位置 & 测点位置描述 \\
\hline 1 & 主断路器安装左上梁 \\
2 & 主断路器安装左上面板 \\
3 & 主断路器安装右上面板 \\
4 & 主断路器安装右上梁 \\
5 & 设备箱安装法兰左上面 \\
6 & 设备箱安装工装法兰左下面 \\
7 & 设备箱安装法兰右上面 \\
8 & 设备箱安装工装法兰右下面 \\
\hline
\end{tabular}

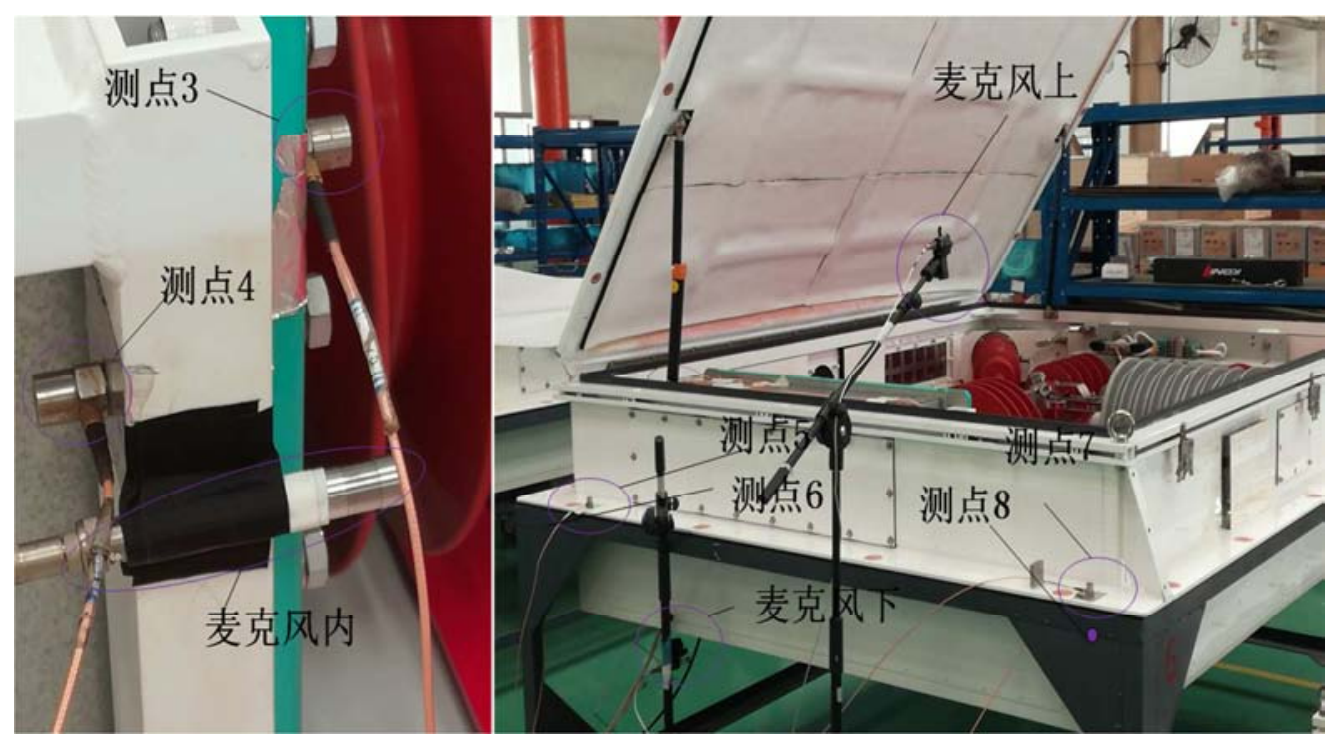

图2 实际测点布置图。 
试验的设备包括数据采集系统（B\&K 3560E），声 学传感器, 振动传感器, 计算机等。通过计算机控制数据 采集系统采集台架试验中振动和声的数据, 通过reflex软 件进行数据的后处理, 可以得到各个减振降噪措施下各测 点位置的振动和噪声情况。

\section{2. 试验分析}

台架试验采取了三种减振降噪的措施, 对设备箱内、 外可操作的部位进行低振低噪声的整改, 数据处理如下:

工况 1 ：设备箱箱体坐在台架上，箱体与台架刚性连 接, 符合实际安装情况, 在高压主断路器安装面板与安装 梁 (箱体) 之间刚性连接, 这是目前列车运行时主断路器 最一般的安装情况, 各位置的振动状况见表 2 。

表2 工况1各测点位置振动幅值。

\begin{tabular}{lll}
\hline 测点位置 & $\mathbf{V C B}$ 闭合 $\mathbf{m} / \mathbf{s}^{\wedge} \mathbf{2}$ & $\mathbf{V C B}$ 断开 $\mathbf{m} / \mathbf{s}^{\wedge} \mathbf{2}$ \\
\hline 1 & 21.4 & 31.9 \\
2 & 22.3 & 28.8 \\
3 & 16.5 & 31.2 \\
4 & 27.8 & 67.2 \\
5 & 4.3 & 6 \\
6 & 2.9 & 6.2 \\
7 & 7.1 & 8.6 \\
8 & 2.5 & 9.1 \\
\hline
\end{tabular}

由表2可以看出, 测点 1 和测点 4 均位于高压设备箱内 安装梁上的振动, 测点 2 和测点 3 位于高压主断路器的安装 面板上, 测点 $1 、 4$ 的振动远高于测点 $2 、 3$ 的振动, 这是由 于主断路器闭合、断开时, 其引起的振动首先传到安装面 板上, 但是由于安装面板较厚, 而箱体安装梁较薄, 安装 面板激起的振动比安装梁的振动小。由于箱体安装梁与箱 体焊接, 且箱体质量较大, 由安装梁传到箱体的振动就降 低了很多。工况1的测试结果符合一般情况下振动的传递 结果, 试验数据真实有效。

工况2: 和工况1的区别在于VCB的安装面板与设备箱 安装梁之间增加一层阻尼垫圈, 且在VCB安装面板与螺栓 接触部位也加一层阻尼垫圈见图3。

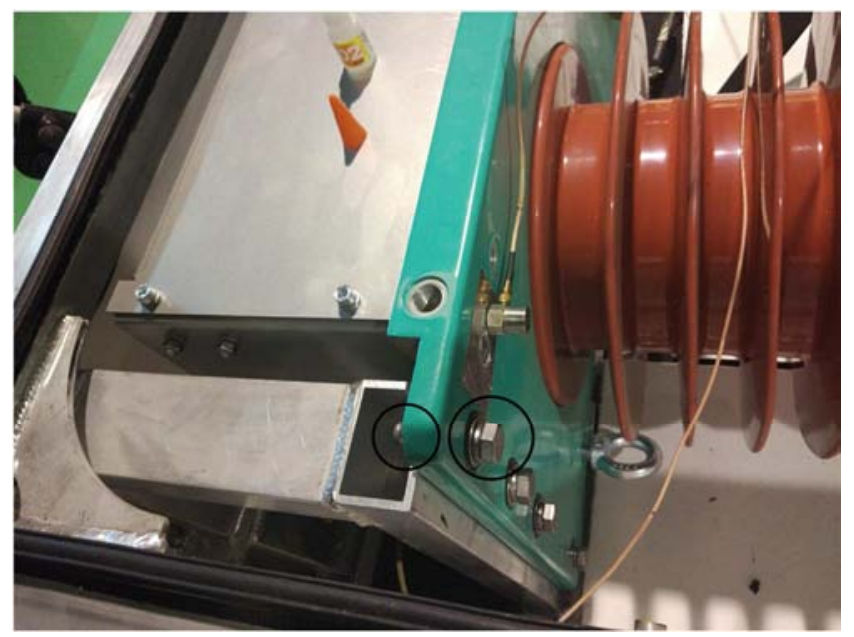

图3 阻尼垫圈安装图。
在工况 1 与工况 2 的条件下进行 VCB 开、合振动冲击试 验, 测试结果如图4所示。

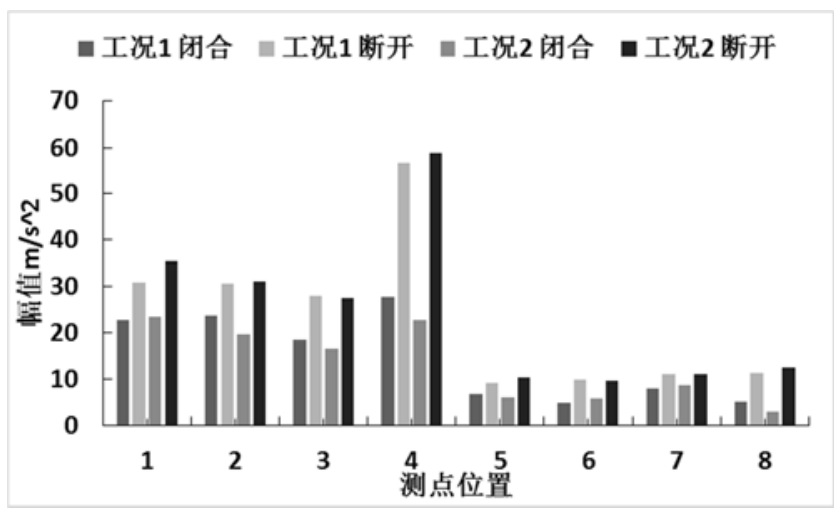

图4 工况1、2振动测点幅值对比图。

由图4不难看出, 测点 2 和测点 3 在 VCB闭合、断开状 态下的振动有所衰减, 但传到测点 $1 、 4$ (安装梁) 的振 动并无减小, $\mathrm{VCB}$ 断开状态下由 $\mathrm{VCB}$ 安装面板传到设备 箱安装梁的振动甚至略有增加。箱体上的测点 5、7的振 动有所增加, 台架上的测点 6 和 8 的振动变化状况规律不 一致, 减振效果不明显。因此, 在主断路器面板和箱体 安装梁之间加装该阻尼垫圈对箱体的振动缓解没有明显 作用。这可能是由于阻尼垫圈较厚, 刚度较大, 不能起 到衰减振动作用的缘故。

工况 3: 在箱体与台架接触面上加装一层减振泡棉, 在固定箱体与台架的螺栓孔旁也加装小块减振泡棉。如图 5 所示。对比工况 1 和工况 3 的振动情况的测试结果, 如图6。 从图6可以看出, 在箱体与台架接触面上加装一层减振泡 棉可以有效缓解设备箱内外振动情况。除位置4测点断开 状态下振动有所增加外, 其余7个位置测点振动都有所下 降, 这是由于设备箱箱体与台架由之前的刚性接触变成了 弹性接触, 减振泡棉不仅衰减了由设备箱传到台架的振动, 也衰减了设备箱自身的振动。分析结果可以证明减振海绵 起到了一定的减振作用。

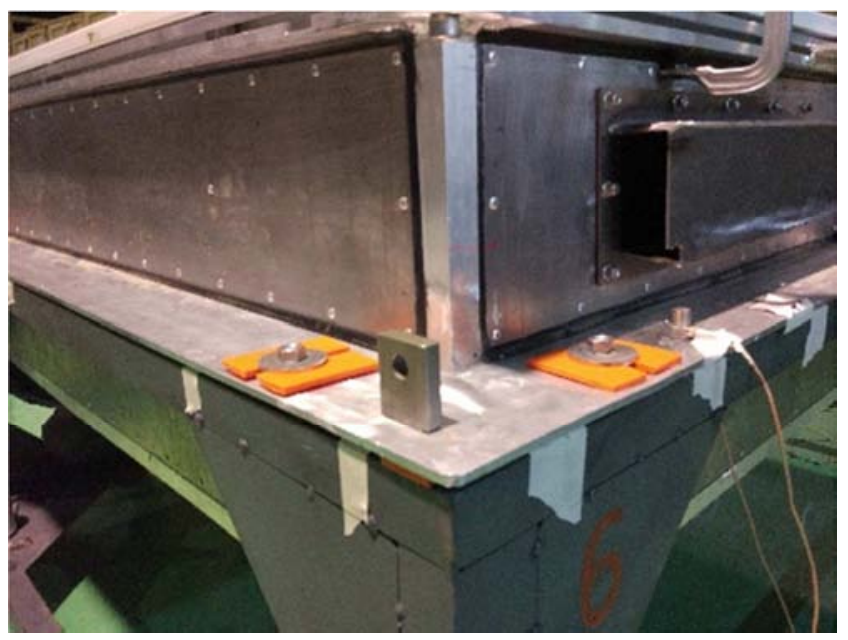

图5 减振泡棉安装图。 


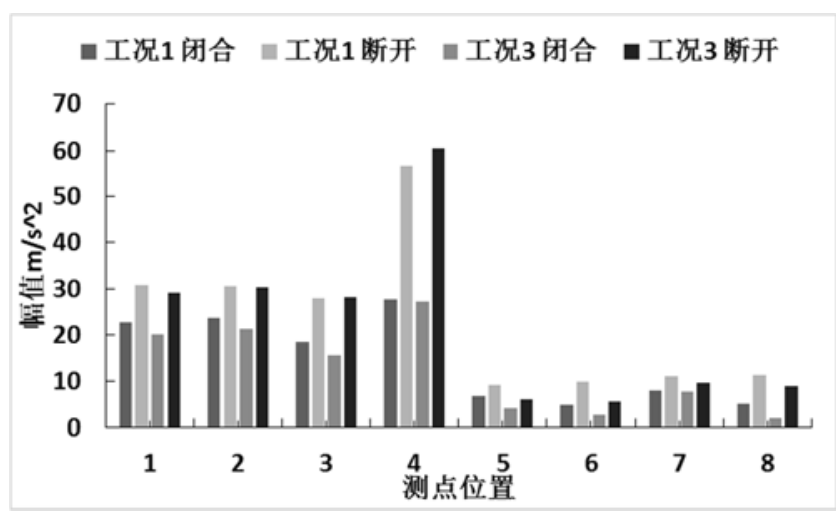

图6 工况1、3振动测点对比图。

工况 4: 在箱体与台架接触面的箱体上安装减振器, 见图7。观察各测点振动噪声情况。图8为工况 1 和工况 4 各振动测点的幅值对比图。

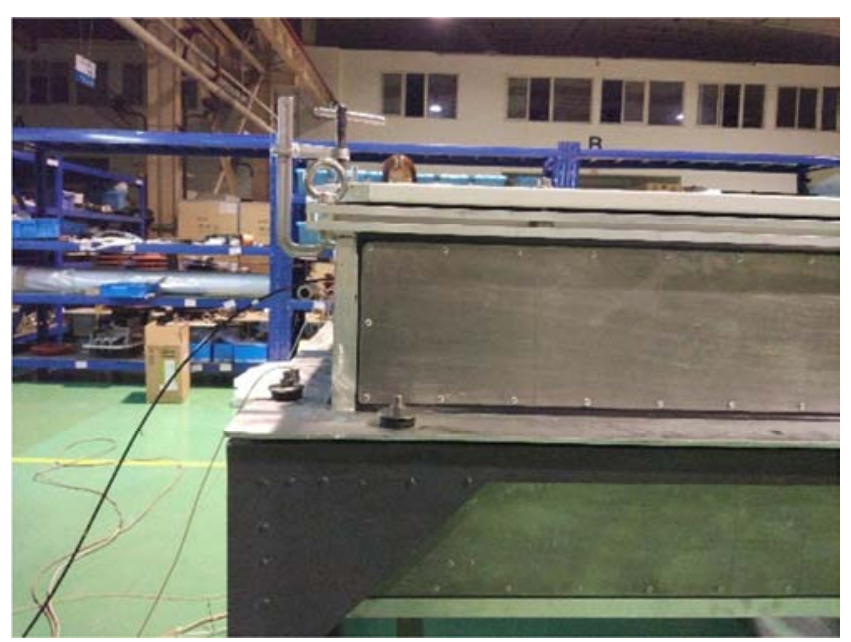

a)实际安装图

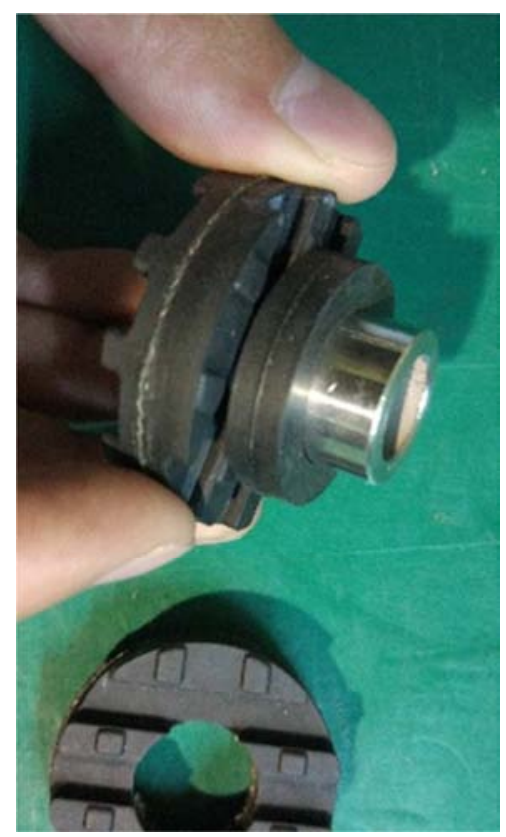

b)减振器图

图7 安装减振器图。

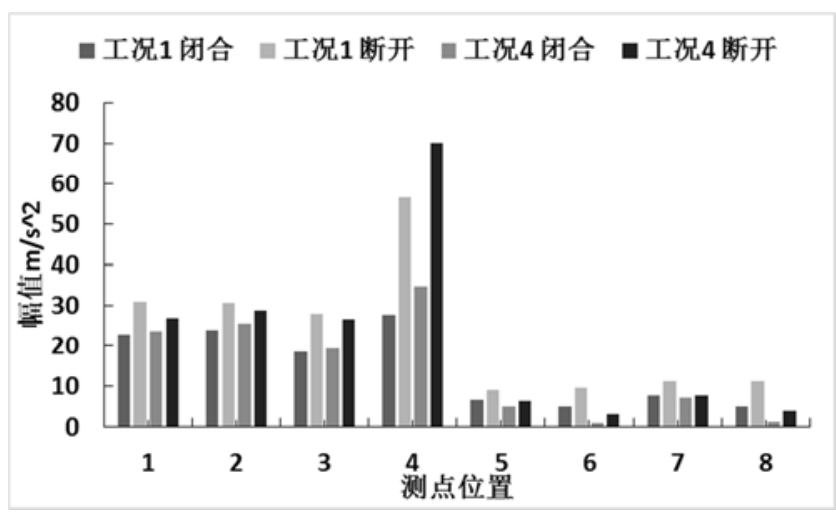

图8 工况1、4振动测点对比图。

由图8可知, $\mathrm{VCB}$ 断开状态下，位于箱体内部 $\mathrm{VCB}$ 安 装面板上的振动相比于工况 1 有所减小，而闭合状态下振 动有所增加, 无论 $\mathrm{VCB}$ 断开、闭合, 设备箱安装梁上的测 点4的振动都有明显增加。而对于箱体外部测点, 设备箱 箱体上的测点 5 和测点 7 的振动有所降低, 测点 6 和 8 的振动 幅值明显降低, 从箱体传到台架的振动明显减小, 这意味 着在列车的实际运行中, 由设备箱传到列车车体的振动较 小, 减振器起到了良好的减振效果。且减振效果强于隔振 泡棉。

试验中, 测点 5 位于安装 $\mathrm{VCB}$ 一侧的设备箱箱体上, 测点 6 位于测点 5 正下方的台架上, 测点 5 和测点 6 为一对测 点, 用其幅值的传递规律来表征实际工况下由设备箱箱体 传到列车的振动。同理, 测点 7 和 8 也为一对测点, 位于远 离安装 $\mathrm{VCB}$ 的一侧。图9为四种工况下测点5-6、7-8的振动 衰减率。

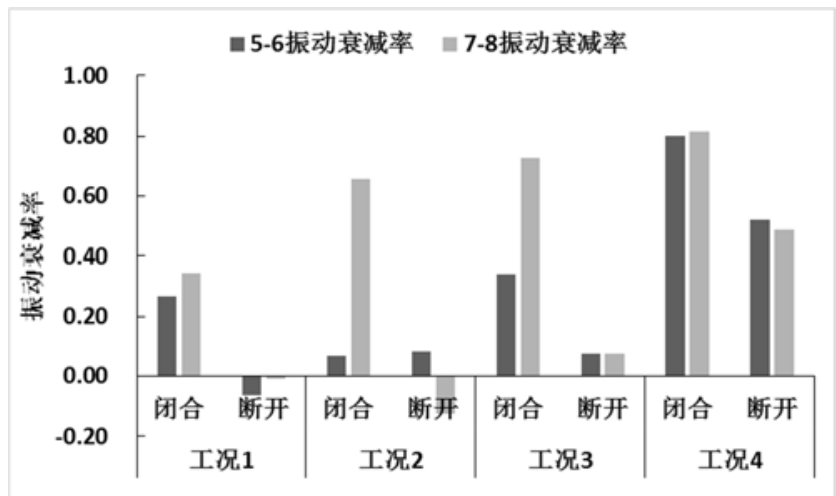

图9 四种工况下振动衰减率对比图。

工况 1 中, $\mathrm{VCB}$ 闭合状态下测点 5 到 6 的振动衰减率为 $27 \%$, 测点 7 和 8 振动衰减率为 $35 \%$, 而断开状态下均为负 值, 这说明, 在断开状态下, 由箱体传到台架的振动被放 大了。工况2中虽然 $\mathrm{VCB}$ 闭合状态下7-8振动衰减率较大, 超过 $60 \%$, 但VCB断开时 7-8的振动被放大, 减振效果不统 一。而在工况 3 和工况 4 下两组测点都展现出明显的减振效 果, 工况4中, $\mathrm{VCB}$ 闭合时由设备箱体传到台架的振动衰 减率可达 $80 \%$ 以上, $\mathrm{VCB}$ 断开时减振率也能接近 $50 \%$, 该 工况下由设备箱体到台架减振率要远远好于工况 3 。

图10为四种工况下VCB闭合、断开时噪声测点幅值: 


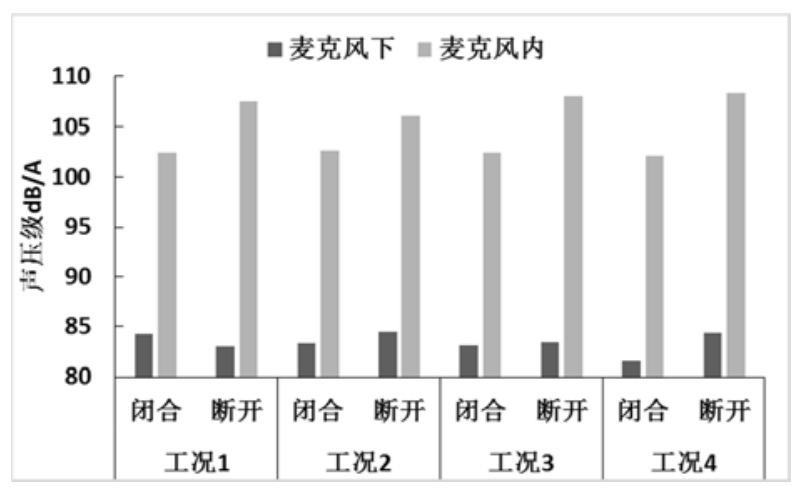

对于工况2、3、4中的箱内噪声测点, 同工况1相比, $\mathrm{VCB}$ 闭合时基本无变化, $\mathrm{VCB}$ 断开时工况2减小, 工况 3 和工况4箱内噪声略有增加, 工况4下噪声值增加最多, 约 为 $0.8 \mathrm{~dB}$ 。对于箱体下部噪声, 与工况 1 相比, $\mathrm{VCB}$ 断开时 其他三种工况的噪声都有增加, 工况2增加最多, 闭合时 噪声都有不同程度的减小, 这意味着由箱内传到箱外的噪 声都有减少, 工况4减少最多, 约 $2.6 \mathrm{~dB}$, 其次是工况 3 , 减少 $1.1 \mathrm{~dB}$, 最后是工况 2 , 噪声值减少不足 $1 \mathrm{~dB}$ 。

单独取工况4下对比测点 $5 、 6 、 7 、 8$ 幅值图进行分析, 见图11。

图10 四种工况下噪声测点对比图。

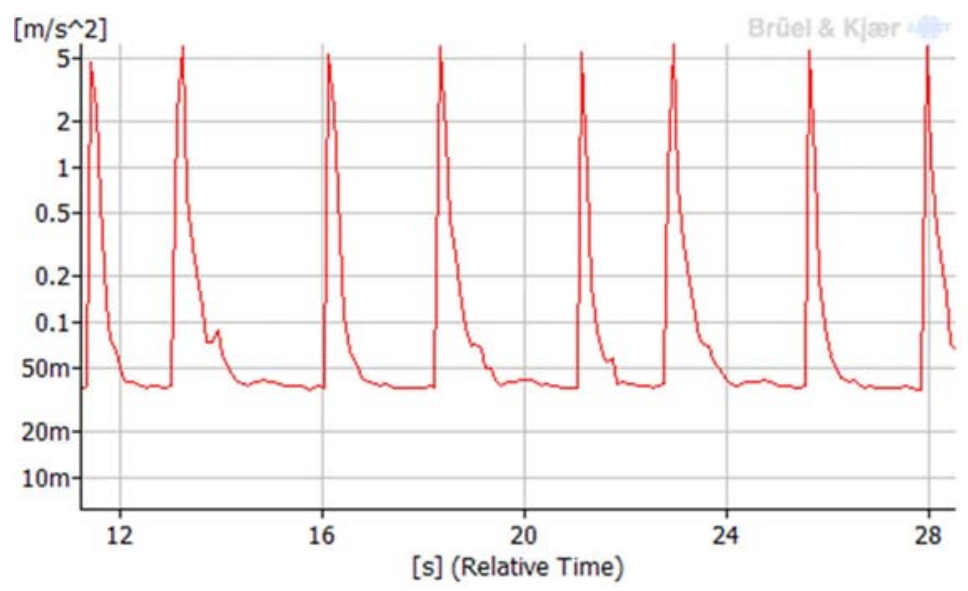

a)测点 5

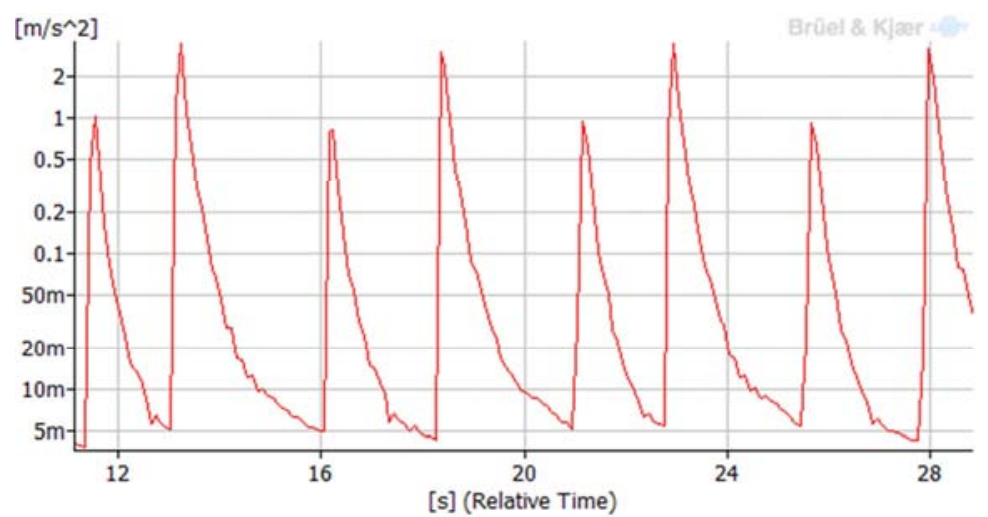

b)测点 6

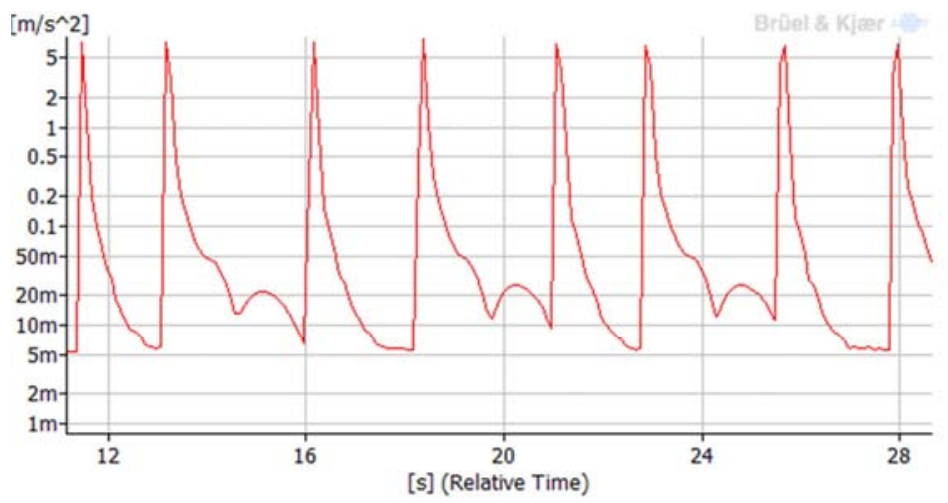

c)测点 7 


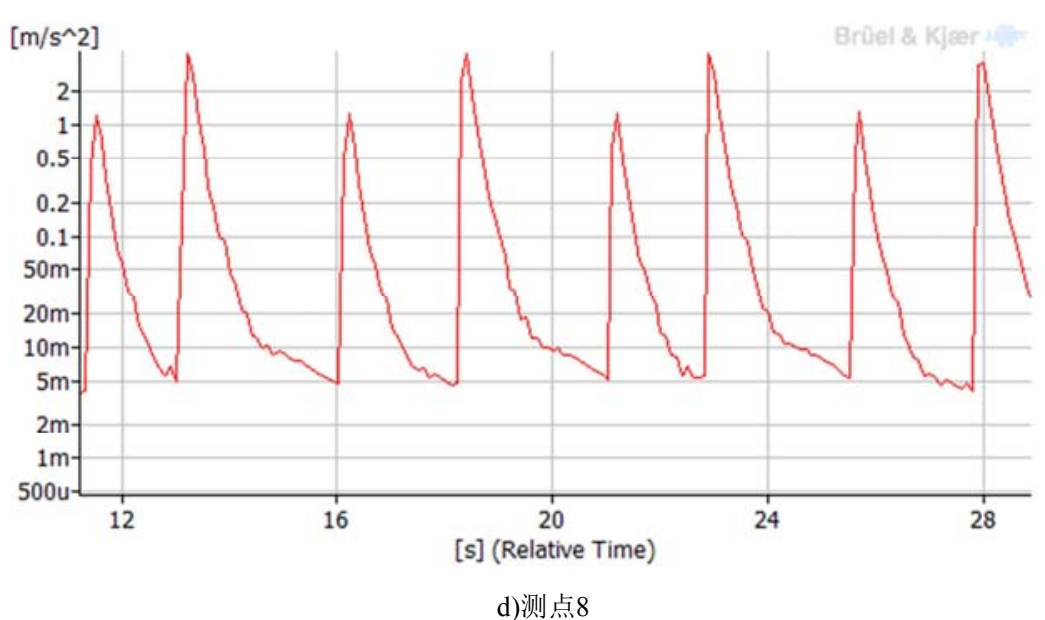

图11 工况4下测点5、6、7、8幅值图。

由图11不难看出, 各测点所示的为 VCB闭合、断开四 个周期的幅值图, 每幅图的起始峰值对应VCB闭合一瞬间 各个测点的幅值。测点 6 和测点 8 变化规律相同, 测点 5 和 测点7变化规律相同。且VCB断开时其振动幅值高于闭合 时的振动幅值。此外, VCB闭合时测点 6 和测点 8 的振动幅 值明显小于VCB 断开时的幅值, 而对于测点 5 和测点 7 , $\mathrm{VCB}$ 断开、闭合时振动幅值基本相当。

为了更好的观察减振器的减振效果, 取工况 4 下 5 和 6 、

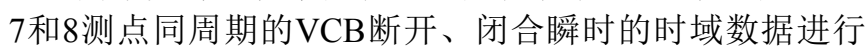
FFT分析, 得到频谱图12-19:

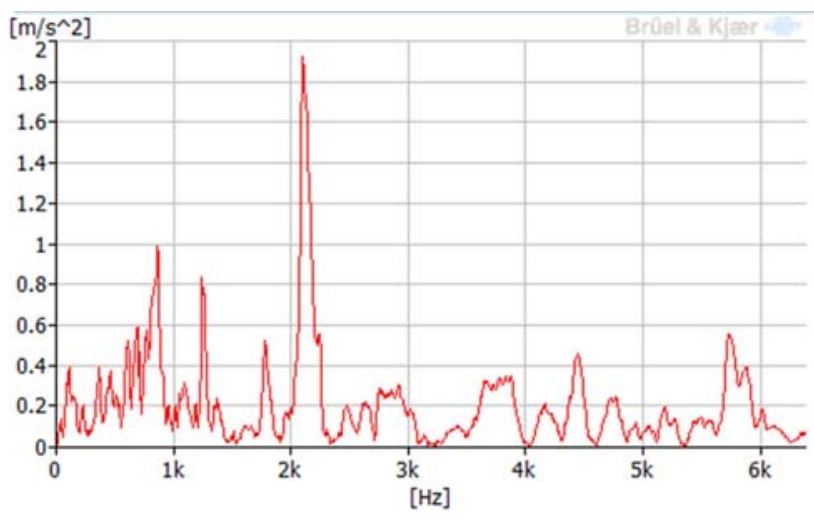

图12 VCB闭合状态测点5FFT图。

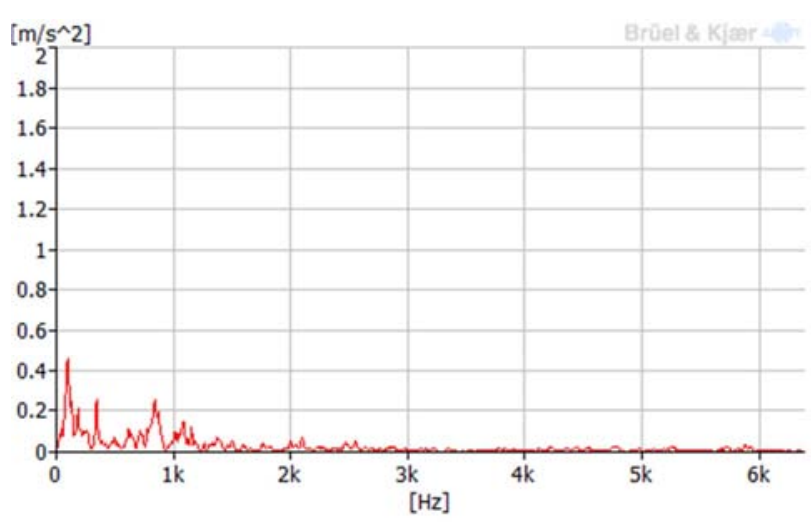

图13 VCB闭合状态测点6FFT图。
对比图12和图13, VCB闭合时箱体振动集中在全频带。 加装减振器可以很好的抑制高频振动, 尤其是位于 $2104 \mathrm{~Hz}$ 的振动峰值, 对低频振动也有抑制作用, 但是对于 $96 \mathrm{~Hz}$ 等个别频率振动有所加强。

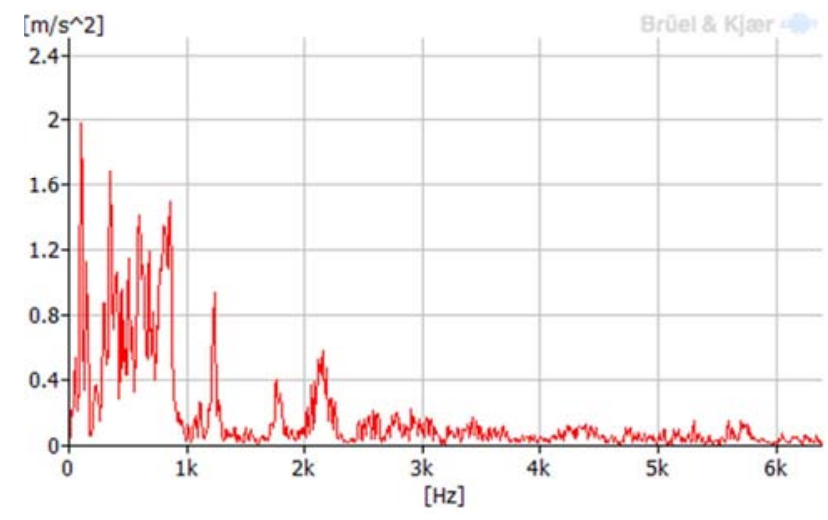

图14 VCB断开状态测点5FFT图。

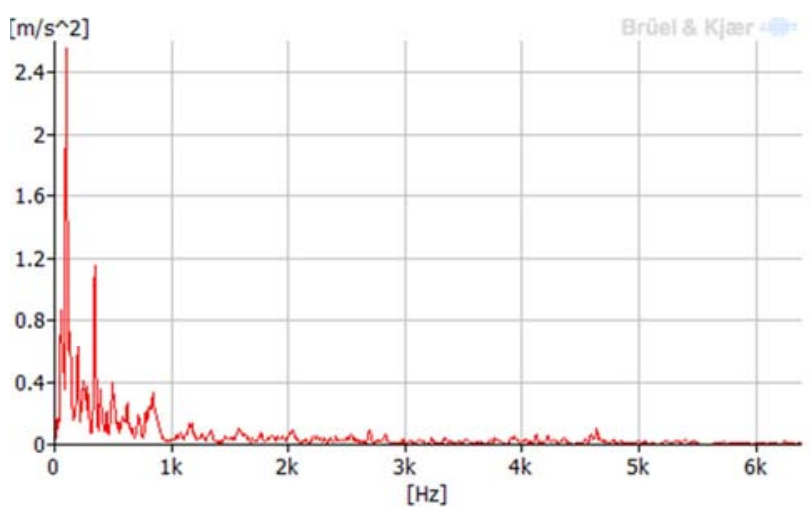

图15 VCB断开状态测点6FFT图。

对比图14和图15可以看出, VCB断开时箱体的低频振 动幅值要远高于高频振动。同闭合状态规律基本一致, 加 装减振器后, $1 \mathrm{kHz}$ 以上振动基本都被衰减, 且 $1 \mathrm{k}-2 \mathrm{kHz}$ 振 动衰减幅度最大, 而 $1 \mathrm{kHz}$ 以下振动虽然大部分频率振动得 到衰减, 但频率为 $96 \mathrm{~Hz} 、 344 \mathrm{~Hz}$ 时振动被放大。

综合以上结果, 可得出结论, VCB闭合状态下箱体振 动集中在全频带, 加装减振器后, 中高频振动被抑制, 低 
频个别频率振动被加强。VCB断开状态下，箱体振动主要 集中在低频, 减振器可以抑制大部分低频振动, 但也会放 大 $96 \mathrm{~Hz} 、 344 \mathrm{~Hz}$ 频率下的振动。

测点7和 8 为远离 VCB安装一侧的箱体、台架上测点, 图16、图17分别为VCB闭合状态下测点7、8的FFT图。

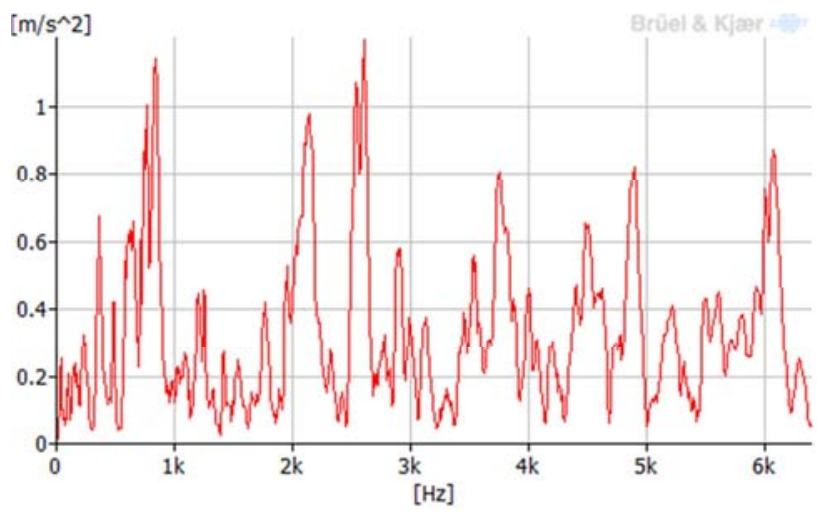

图16 VCB闭合状态测点7FFT图。

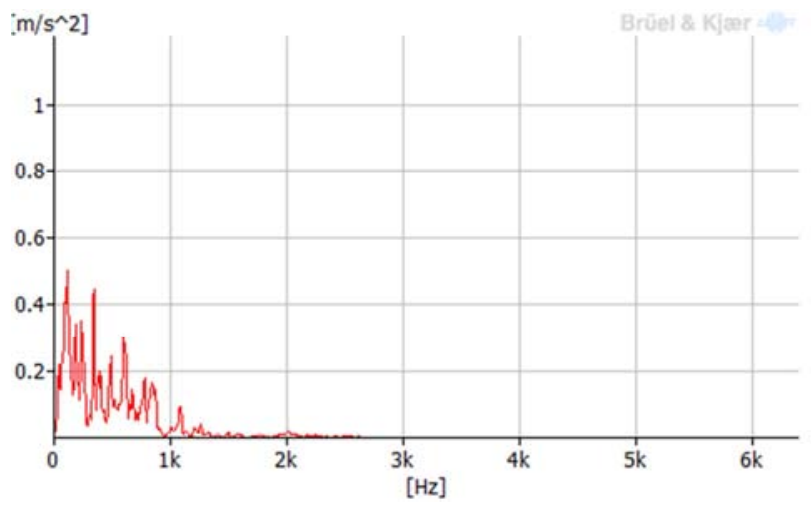

图17 VCB闭合状态测点8FFT图。

对比图16和 $17, \mathrm{VCB}$ 闭合状态下减振器对整个频带都 有较好的减振效果, 但在低频区域, 尤其是低于 $344 \mathrm{~Hz}$ 的 频率振动被放大。

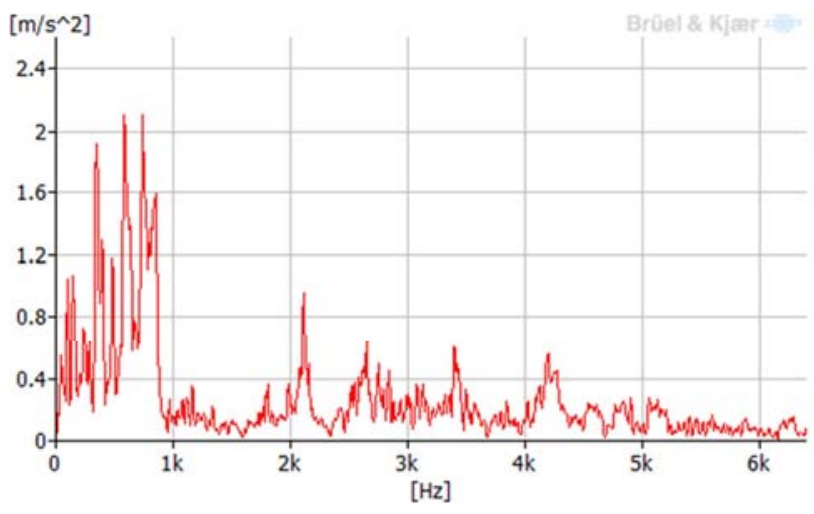

图18 VCB断开状态测点7FFT图。

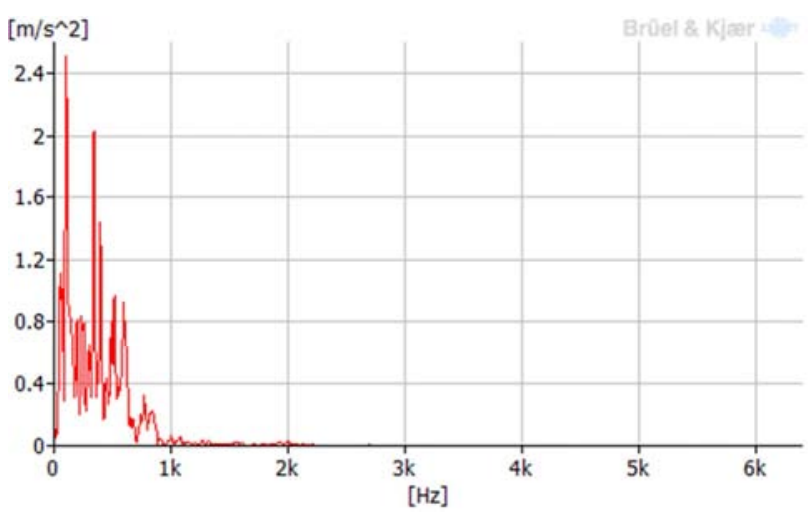

图19 VCB断开状态测点8FFT图。

图18和图19为VCB断开状态下测点7、8的FFT图。

同VCB闭合状态下的规律基本相同，高频振动被很好 的抑制，低频下大部分频率的振动被衰减，336Hz、104Hz 的振动被放大。

通过对箱体、台架上四个测点的频谱分析, 可得出该 橡胶减振器的减振规律: 对于中高频的振动, 该橡胶减振 器可以很好的抑制, 对于低频振动, 该减振器也能较好的 工作，可以衰减低频下大部分频率的振动，但是对于个别 频率，尤其是集中在 $96 \mathrm{~Hz}$ 到 $344 \mathrm{~Hz}$ 频带内的诸多频率，减 振器只起到放大作用。因此, 在减振器的实际应用中还应 配合其他低频减振的措施，以便达到更好的减振效果。

\section{4. 结论}

通过台架试验, 对不同的减振降噪措施进行了检验, 可得如下结论: 主断路器断开时的振动和噪声都明显高于 闭合时的振动, VCB安装面板与箱体安装梁之间加装阻尼 垫片对箱体的减振没有明显效果。向设备箱与台架的接触 面上增加减振器或减振泡棉, 有助于衰减由VCB开合经箱 体传到台架的振动, 且橡胶减振器减振效果要好于减振泡 棉。VCB闭合时由箱体到台架的振动衰减率超过 $80 \%$, 断 开状态下的减振率也能接近 $50 \%$, 且使用减振器进行减振 时, $\mathrm{VCB}$ 闭合状态下箱体下部噪声减少 $2.6 \mathrm{~dB}, \mathrm{VCB}$ 断开 时箱体下部噪声略有增加。因此, 加装橡胶减振器是 VCB 设备箱减振降噪较为理想的选择, 但实际中应配合其他低 频减振措施一起工作。

\section{致谢}

本文受为中国铁路总公司科技研究开发计划资助, 课 题编号为(2015Z003-C、2015Z003-A)。

\section{参考文献}

[1] 丁勇.高速动车组车体操作过电压特性仿真分析与试验验 证[J].中国铁路,2017(09):68-72+78。

[2] 莫坚.SS_9改进型机车受电弓及主断路器控制电路的改进 设计 $[\mathrm{J}]$.机车电传动, 2007(03):71-73。 
[3] 史丹.动车组高压系统操作过电压及其抑制技术研究[D]. 北 京:北京交通大学,2015:3。

[4] 手旺.基于电流信息的列车不断电过分相技术研究 $[\mathrm{D}]$. 北京: 北京交通大学,2014:4。

[5] 李富军,韩建新.高压真空断路器的应用技术探究[J].中国高 新技术企业,2016(34):71-72。

[6] 汪洋. 电力系统中高压真空断路器常见故障原因分析及处 理[J].内燃机与配件,2017(08):105-106。

[7] 孔祝英,李执希. 电力机车新型智能真空主断路器的研制 [J]. 机车电传动, 2010(05):54-56+69。

[8] 马世骁,林莘,王钰等. 高压断路器寿命可靠性判断法[J].辽宁 工程技术大学学报,2006,25(S2):170-172。

[9] 刘光娜, 唐风梅.动车组车载真空断路器检修易擦伤问题分 析及工艺改进 $[\mathrm{J}]$.科技视界,2015(10):78+222。
[10] 欧阳乐成, 吴广宁, 李天鸷等.频繁开断下车载真空断路器寿 命试验方法的讨论 [J]. 高压电器, 2012,48(9):83-87+91。

[11] 李天鸷,吴广宁,欧阳乐成等.高速列车过分相段下真空断路 器的电寿命研究 [J]. 机车电传动,2012(04):26-29。

[12] 韩伟, 廖乡萍, 刘冰.动车组主断路器反馈信号故障原因分析 及应对措施 $[\mathrm{J}]$. 电力机车与城轨车辆, 2017,40(04):81-83。

[13] 赵良省. 噪声与振动控制技术 [M]. 北京: 化学工业出版 社,2005:11-13。

[14] 马森月. 高速铁路噪声源识别—津秦铁路客专试验研究[D]. 北京;北京交通大学,2014:5。

[15] 谭迈之.机车真空主断路器试验台的研制 [J].电力机车与城 轨车辆,2015,38(05):65-69。 